\title{
ro \\ DESIGN AND CONSTRUCTION OF AUTOMATED EGGS INCUBATOR FOR SMALL SCALE POULTRY FARMERS
}

\author{
Ajani Adegbenro Sunday ${ }^{1}$, Olusoji Amos Ogunbode ${ }^{2}$, Egbeyale Godwin Babatunde ${ }^{3}$, Adeniji Muyideen \\ Olalekan ${ }^{4}$ \\ E-Mail Id: adegbenro.ajani@kwasu.edu.ng ${ }^{1}$, aoogunbode19@pgschoollautech.edu.ng ${ }^{2}$, \\ godwin.egbeyale@kwasu.edu.ng ${ }^{3}$, muyideen.adeniji@ kwasu.edu.ng ${ }^{4}$ \\ 1,3,4 Department of Physics and Material Sciences, Kwara State University, P.M.B 1530, Malete, Ilorin, \\ Nigeria \\ ${ }^{2}$ Department of Pure and Applied Physics, Ladoke Akintola University of Technology, P.M.B 4000 \\ Ogbomosho, Oyo State, Nigeria
}

\begin{abstract}
This paper demonstrated the design, construction and performance evaluation of automated eggs incubator for poultry farmers. The aim of this research was to produce a low cost user friendly modern incubator to increase the production of day old chicks for small and medium scale poultry farmers. The incubator has the hatching capacity of 100 eggs. Factors that were considered during the performance evaluation of the incubator were humidity, $55 \%$ and temperature, $37^{\circ} \mathrm{C}$ during the first 18 days and were maintained at $37.5{ }^{\circ} \mathrm{C}$ till hatching. Turning of eggs was achieved with the use of tilting trays mechanism controlled by a programmed electric motor. The trays were lifted through an angle of $40^{\circ}$ either side of horizontal at every hour and lasted for four minutes. 100 fresh, healthy, well developed and matured eggs were used to test the incubator. The result of the test revealed the following average values- fertile eggs 95 , infertile eggs 5 , hatched eggs 85 and hatchability of $89.47 \%$ was achieved.
\end{abstract}

Keywords: Poultry; Incubator, egg.

\section{INTRODUCTION}

Incubation is a technology that provides opportunity for farmers to produce chicks from eggs without the consent of the mother hen. It is one of the fastest ways of transforming eggs to chicks. The most important difference between natural and artificial incubation is the fact that the natural parent provides warmth by contact rather than surrounding the egg with warm air. It is an exciting adventure to under study chicken egg and its development from the incubating stage to the emergence of the chick from the shell. The developing chick in an egg is called the embryo, and a careful study of the different stages of embryonic development will uncover many interesting facts. Incubation of eggs will show the effects of heat, air, and moisture their hatchability. One will find out how an egg is formed, its different parts and their functions, and how a chick embryo develops for thousands of years (Benjamin and Oye, 2012).

Both the Chinese and the Egyptians are credited with originating artificial incubation procedures. The Chinese developed a method in which they burned charcoal to supply the heat while the Egyptians constructed large brick incubators that they heated with fires right in the rooms where the eggs were incubated. Over the years incubators have been refined and developed so as to be almost completely automatic. Modern commercial incubators are heated by electricity, have automatic egg-turning devices, and are equipped with automatic controls to maintain the proper levels of heat, humidity, and air exchange. Both still-air and forced-draft incubators are used in hatcheries. However, all the new incubators are forced-draft; that is; they have fans to circulate the air. They are capable of maintaining more even temperature, humidity, and oxygen levels than stillair incubators.

Since the 1930s, the poultry industry has become one of the most efficient producers of protein for human consumption. It rapidly expanded during World War II because of the shortage of beef and pork, which require a much longer time to develop; only seven weeks are required to produce a broiler and five months to produce a laying hen (Singh, 1990).

More recently, in response to public concern over dietary fat, poultry has however becomes a popular substitute for beef, pork and other dairies.

The world's population is growing at an alarming rate and so is the demand for protein in our diets, especially in rural areas; poultry is a good source of protein and it is affordable. A broody hen, raised to hatch eggs and raise the chicks, can hatch just about 10-12 eggs at once in 21 days, which reduces its productivity as it takes time to incubate and hatch the chicks. In contrast, some large birds, such as condors and albatross, may lay only a single egg every two years. For the world growing population, relying on this natural type of incubation is not enough, hence the need for artificial incubation. This way, a female bird just concentrates on laying eggs while the incubation is done for her artificially (C.E, 1986; C.E, 1986).

\section{METHOD AND DESIGN}

The flow chart representation for the design of this research is described in fig. 2.1.

DOI Number: https://doi.org/10.30780/IJTRS.V05.I08.001 


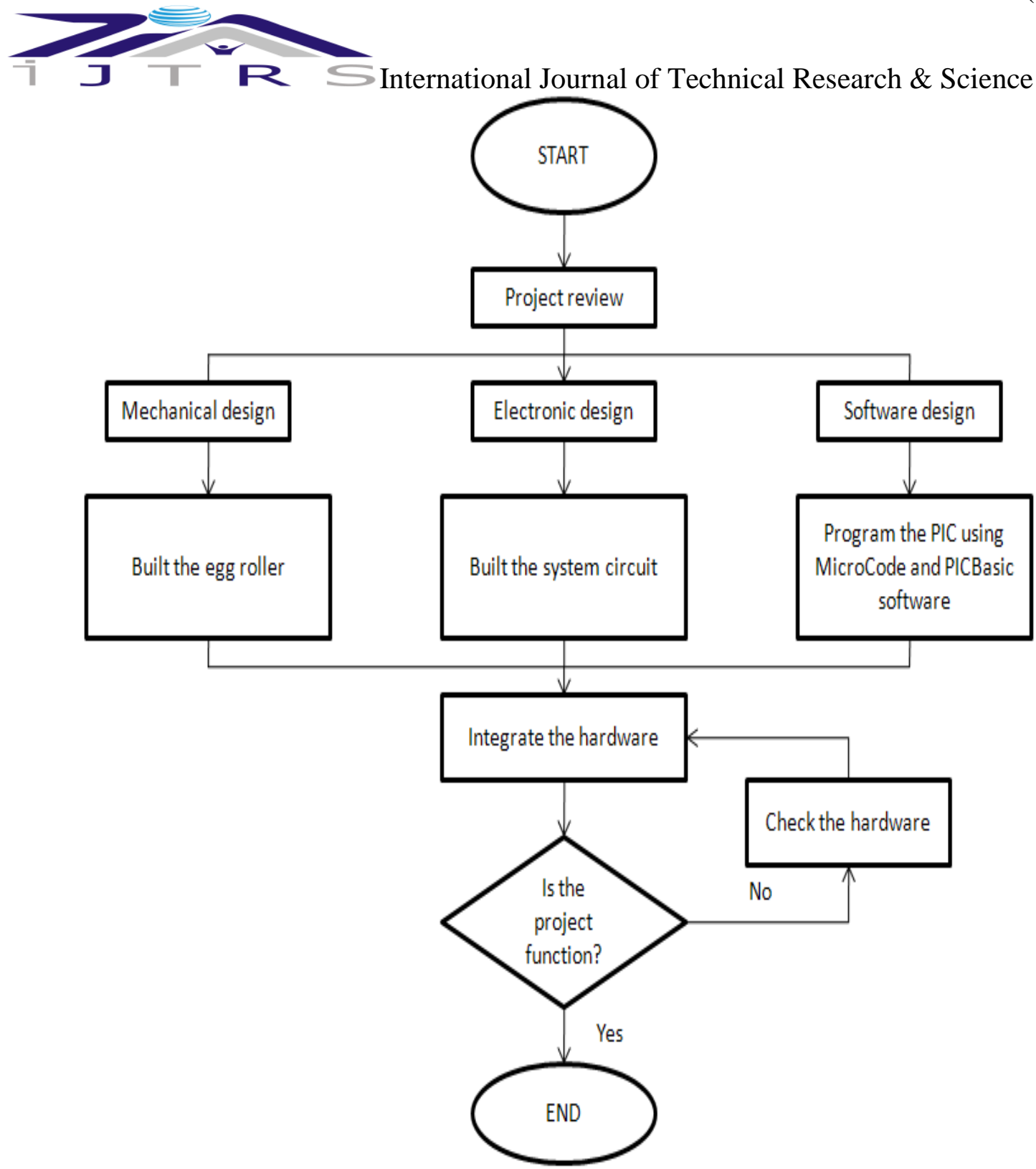

Fig. 2.1 Flow Chart of an Incubator

\subsection{The Research Development}

This research development was divided into three main sections namely; mechanical design, electronic design and software design. These parts were combined together to perform the automatic Egg Incubator System for various types of eggs. The incubator was matched up with the temperature and humidity sensor that can measure the condition of the incubator and automatically change to a suitable condition for the eggs.

The location of the incubator and hatchers' units were placed indoor to protect them from major weather changes. It is essential that the room has a good ventilation system to supply sufficient fresh air to the system. Keeping the units indoors makes it easier to maintain uniform temperature and humidity, which are two other factors to be varied with the movement of the tray. In this research, the light was used to provide suitable temperature to the egg. The percentage humidity in the incubator was made consistent by controlling the fan and water inside the incubator, to ensure humidity as well as ventilation is in good operational condition (MohdAdid, 2008).

Liquid Crystal Display (LCD) was used to display the status condition in the incubator which appears on the LCD screen. To make sure all parts of egg was heated by lamp, stepper motor was employed to rotate iron rod at the bottom side and automatically change the position of egg.

The entire element will be controlled using programmable integrated circuit (PIC). The PIC is a type of microcontroller that can process a data from sensor and will execute the control element to change the condition of incubator.

The microcontroller based egg incubator with temperature meter display was designed in six units. The units were connected together to derive the functional hardware. At the input is a temperature sensor LM358; a linear temperature sensor from national semiconductor. This is the unit that senses the heat from the incubator chamber. The second unit is the ADC 0804; this unit is the analog to digital converter (A/D) that converts analog signal to digital 8-bit parallel output. This data is fed into port 0 and 1 respectively of the 89C51 
J $\quad R$ S International Journal of Technical Research \& Science

microcontroller. The third unit is the 89C51 micro-controller designed to perform the micro-program control. The fourth unit is a transistor static switch realized with two (2) PNP bipolar junction transistors; the BC327. These two transistors switch from the least significant bit (LSB) to the most significant bit (MSB) of the two (2) seven segment displays that display between $0^{\circ} \mathrm{C}$ to $99^{\circ} \mathrm{C}$. The fifth unit is the interface card realized with the combination of a transistor switch and an electromagnetic relay. Here the heater is connected as an external device through a 13-amps socket outlet. The final and the sixth unit is the digital temperature display configured with the two (2) seven segments common cathode type Light Emitting Diodes (Anthony Obidiwe1, Design and Implementation of a Microcontroller Based).

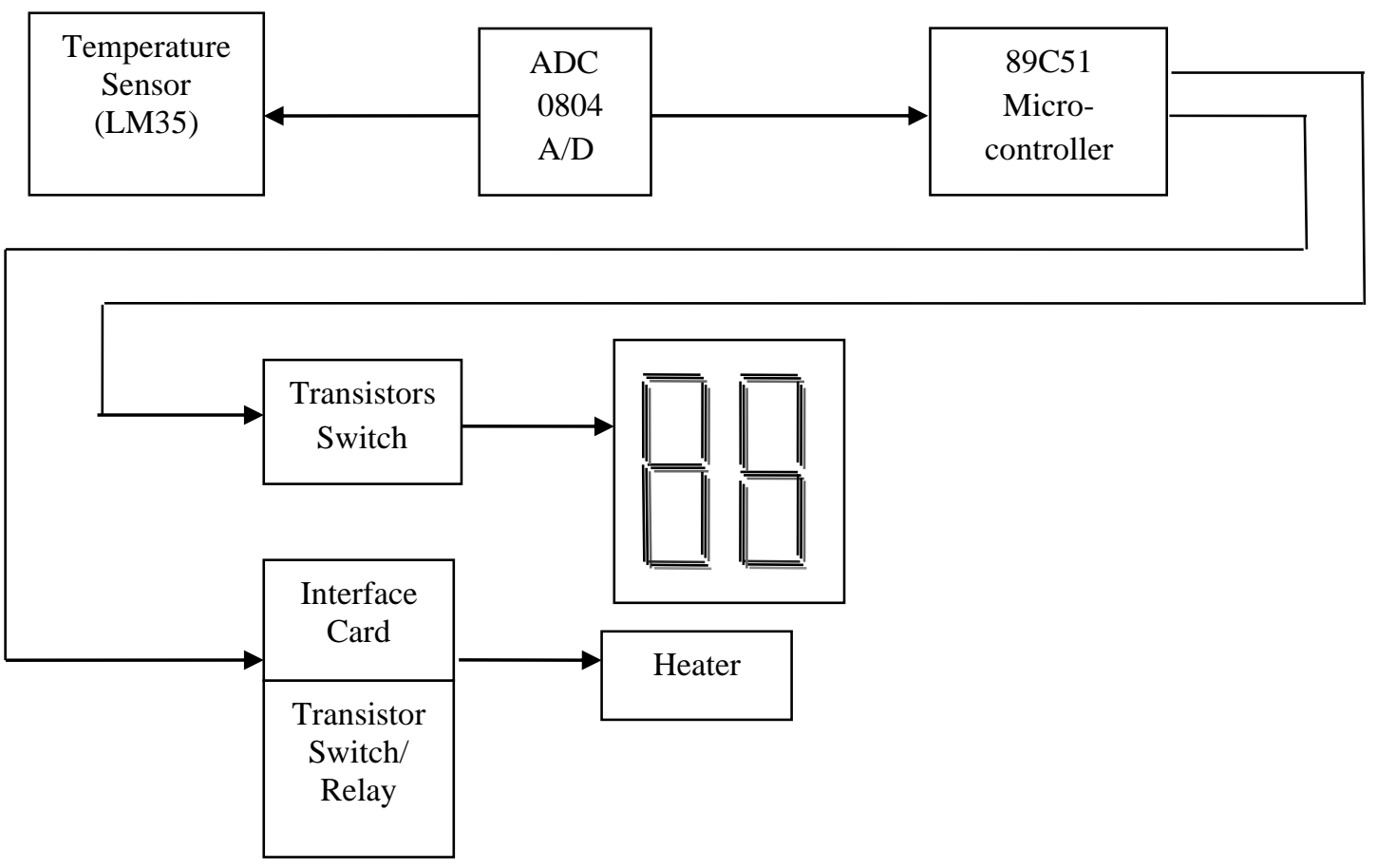

Fig. 2.1 Block Diagram of the System and its Component Units

\subsection{System Specifications}

The system specifications are divided into various sections as explained below

$>$ The Temperature sensor must be a linear temperature sensor, with adjustable current source such as the LM35. Alternatively the LM334 or LM391 from National Semiconductor can be utilized.

$>$ 2. A quasi-crystal of $10 \mathrm{MHz}$ must be hooked to the micro controller to maintain a steady clock frequency for the microcontroller internal clock.

$>$ 3. A common cathode ssd, RS25 miniton display is chosen as display for the system.

$>$ 4. A static switch for the ssd through the port 2 and port 3 must be configured using PNP silicon bipolar junction transistor to pave way for conformity to their individual biasing requirements based on the input output (I/O) logic.

$>$ The electromagnetic relay must exhibit the following parameters: Coil resistance of $400 \Omega$, maximum current rating of 10Amps, and voltage of $12 \mathrm{~V}$ max.

$>$ The microcontroller must be fortified with a power up reset at the pin 9, precisely manually operated to reset the system at any time.

\subsection{Mechanical Design}

The research development started with the mechanical design. It is consists the development of incubator casing and built-in egg roller.

\subsubsection{Casing of Incubator}

Fig. 2.3 shows the casing incubator. The following materials were used in the development of the egg incubator: plywood, fan, thermostat, heating element, wet and dry bulb thermometer, relays, piece of glass, wires, shaft, top bond glue, electric motor, paint, bolts and nuts, transformer and bearings. These are employed for;

$>$ Determination of appropriate materials and dimension incubator box.

$>$ Parameter of the temperature control loops/ programming.

When it comes to the design of an incubator, heat required and transferred are critical factors and are of major importance. Temperature and relative humidity in the incubator are dependent on the heat supplied and level of ventilation. Adequate heat supply and ventilation enhance air circulation and heat transfer (Benjamin and Oye, 2012). 

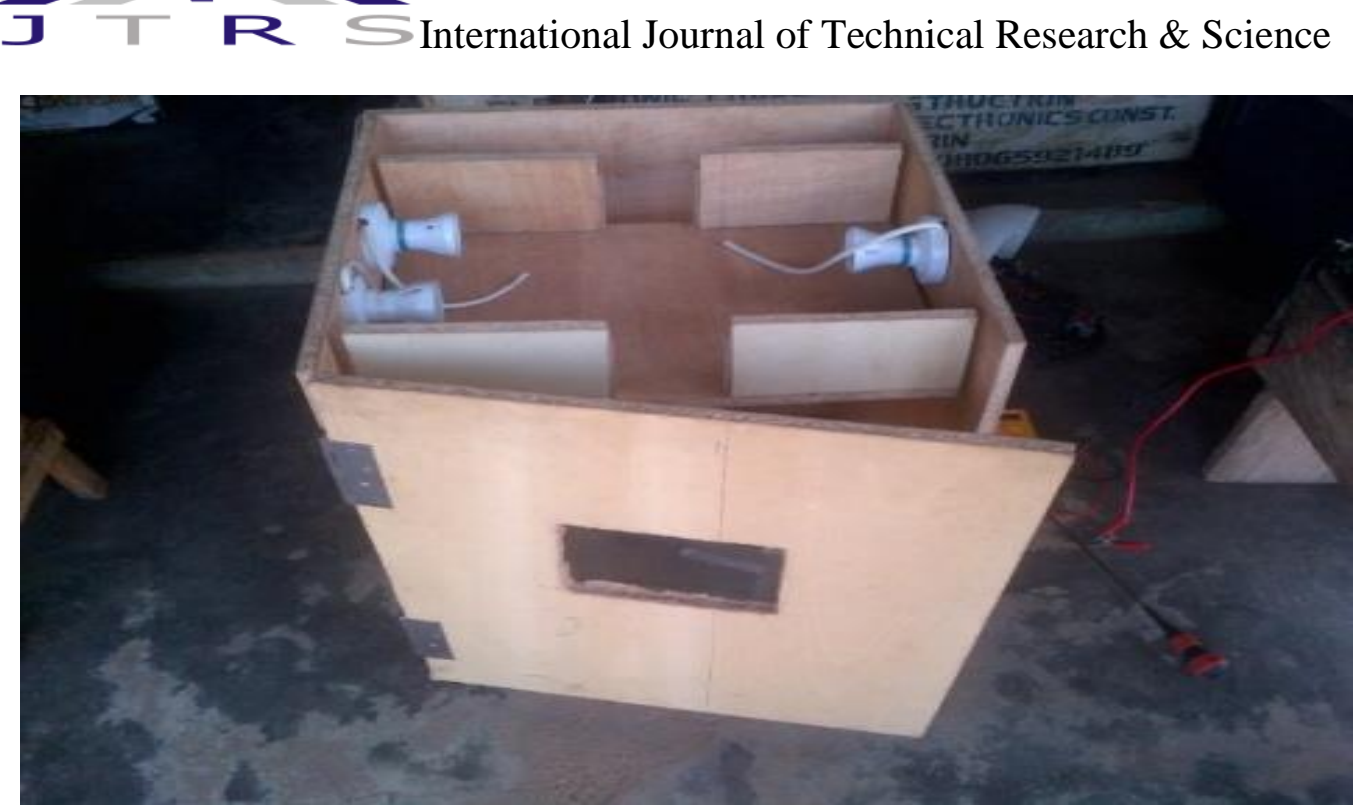

Fig. 2.2 Casing of Incubator

\subsubsection{Egg Roller}

The egg roller is very important in order to change the position of eggs. The position of egg must be changed many times every day until hatching. An idea to designing the egg roller such as conveyer was necessitated which requires some bearing and belting to change the position of egg in smoothly. The material used to build the egg roller is an aluminum plate and aluminum rode. It was employed to reduce cost of construction because about $60 \%$ the material used were from cycle materials. Before constructing the egg roller, all measurements were recorded to ensure accurate construction and casing.
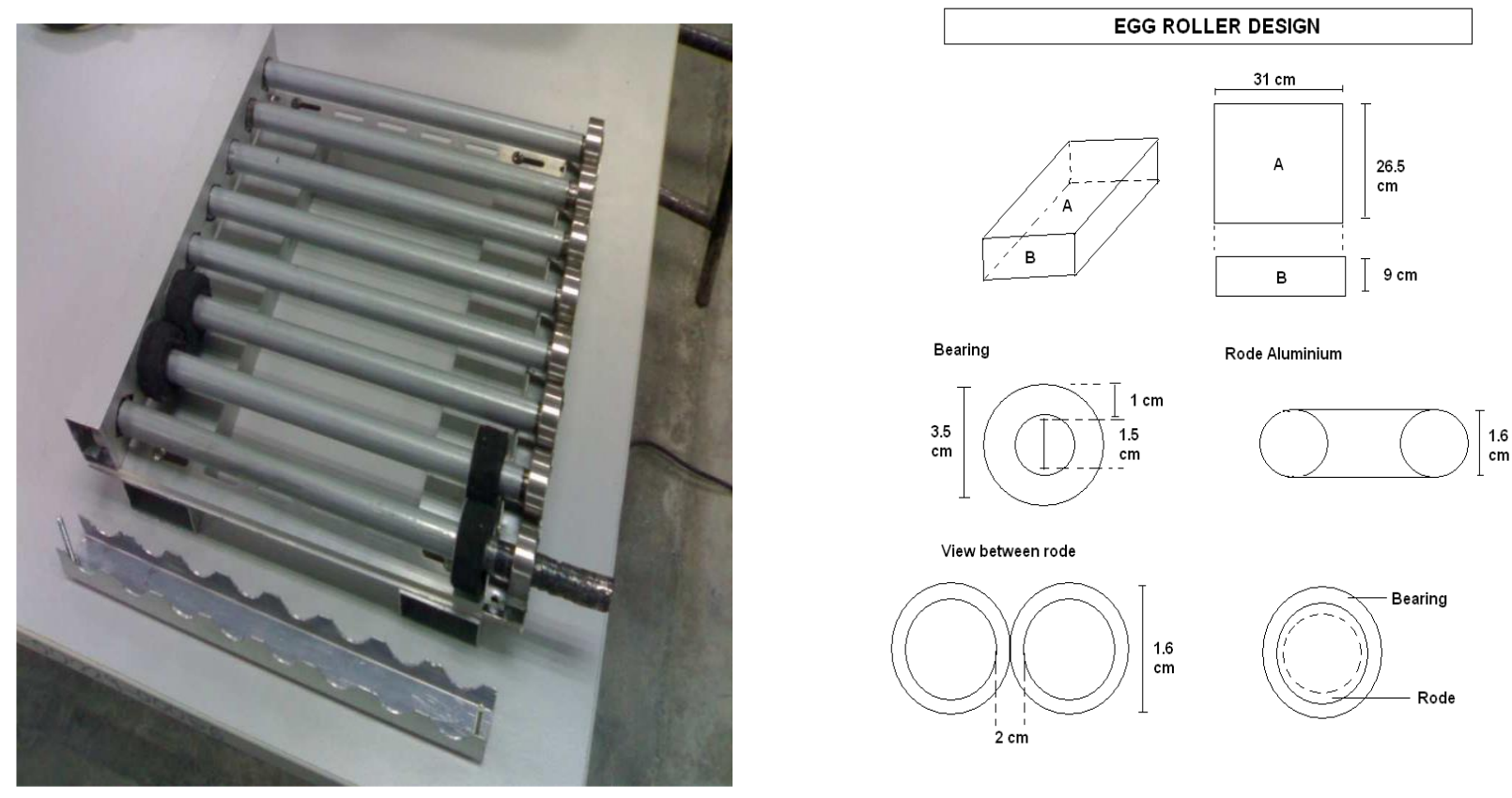

Fig. 2.3 An Eggs Roller Design

\subsection{Design Analysis}

\subsubsection{Determination of Humidity}

The humidity required for the incubation of poultry eggs was calculated as the mass of water vapor per unit volume over unit volume of air. It keeps the egg from losing too much of moisture during the incubation process. However, humidity depends on mass flow of air, temperature and speed of the fan, the following expression was used to determine humidity (D., 1990).

$$
\begin{gathered}
H=\frac{m_{v}}{v} \\
\rho_{v} V=m_{v} R_{v} T \\
\text { RS.V05.I02.002 } \\
\text { www.ijtrs.com } \\
\text { www.ijtrs.org }
\end{gathered}
$$




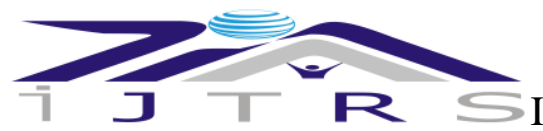

International Journal of Technical Research \& Science

$$
\mathrm{H}=\frac{\mathrm{v}}{\mathrm{R}_{\mathrm{V}} \mathrm{T}}
$$

Where; $\mathrm{H}=$ Humidity, $\mathrm{m}_{\mathrm{v}}=$ Molar mass of water, $\rho_{\mathrm{v}}=$ Energy density or heat density $\mathrm{R}_{\mathrm{V}}=$ gas constant, $\mathrm{T}=$ temperature, $\mathrm{V}=$ volume

\subsubsection{Determination of Heat Generation}

Heat generated from the incubator is determined as $\mathrm{MC} \Delta \mathrm{T}$, which implies that the heat required to raise the temperature of the incubator will be the heat required to raise the temperature of the air, eggs, glass, egg tray, water and wooden wall, which was determined with the heats formula below; For heat generated inside the incubator:

$$
\mathrm{Q}_{\mathrm{I}}=\mathrm{M}_{\mathrm{I}} \mathrm{C}_{\mathrm{I}} \Delta \mathrm{T}
$$

Therefore, heat required to raise the temperature of the air and the eggs can be determined using the formula listed below;

For the Air;

$$
\mathrm{Q}_{\mathrm{A}}=\mathrm{M}_{\mathrm{A}} \mathrm{C}_{\mathrm{A}} \Delta \mathrm{T}
$$

For the Eggs

$$
\mathrm{Q}_{\mathrm{e}}=\mathrm{M}_{\mathrm{e}} \mathrm{C}_{\mathrm{e}} \Delta \mathrm{T}
$$

For the Water

$$
\mathrm{Q}_{\mathrm{w}}=\mathrm{M}_{\mathrm{w}} \mathrm{C}_{\mathrm{w}} \Delta \mathrm{T}
$$

For the Plywood

$$
\mathrm{Q}_{\mathrm{p}}=\mathrm{M}_{\mathrm{p}} \mathrm{C}_{\mathrm{p}} \Delta \mathrm{T}
$$

Where; $\mathrm{Q}=$ heat quantity, $\mathrm{C}=$ specific heat capacity, $\Delta \mathrm{T}=$ change in temperature, $\mathrm{m}=$ molar mass

Also the total heat required to raise the temperature inside the incubator was calculated using the summation of all the heat that was required inside incubator, according to the Parameters listed, then the total heat required is given as;

\subsubsection{Heat Loss}

$$
Q_{I}=Q_{A}+Q_{e}+Q_{T}+Q_{w}+Q_{P}+Q_{g}
$$

Due to the loss of heat during the lagging of wooden wall, a $100 \%$ work is not certain, heat required will be loss by conduction and heat loss can be determined by using the following expression; Considering the plane layer of thickness $\mathrm{dx}$ with one face maintained at a temperature $\mathrm{T}$ and the other end $(\mathrm{T}+\Delta \mathrm{T})$ (A.K., 2001). The rate of heat flow is given by;

$$
\mathrm{Q}=-\mathrm{kA}\left(\frac{\mathrm{dT}}{\mathrm{dX}}\right)
$$

Since the flow is a steady flow, i.e. it does not vary with time.

So

$$
\begin{aligned}
& \mathrm{QdX}=-\mathrm{KAdT} \\
& \mathrm{Q}=-\mathrm{KA}\left(\frac{\mathrm{T}-\mathrm{T}_{\mathrm{C}}}{\mathrm{X}}\right)
\end{aligned}
$$

Then the heat loss during the incubation will be given as:

Top and Bottom Wall

$$
\mathrm{Q}_{\mathrm{PT}}=-\mathrm{K}_{\mathrm{P}} \mathrm{A}_{\mathrm{P}}\left(\frac{\mathrm{T}-\mathrm{T}_{\mathrm{c}}}{\mathrm{x}}\right) \times 2
$$

Side walls

$$
Q_{P S}=-K_{P} A_{S}\left(\frac{T-T_{c}}{x}\right) \times 2
$$

Back Wooden Wall

$$
Q_{P B}=-K_{P} A_{B}\left(\frac{T-T_{c}}{X}\right)
$$

Front Wooden Wall

$$
Q_{P F}=-K_{P} A_{p F}\left(\frac{T-T_{c}}{X}\right)
$$

Glass Window

$$
Q_{g w}=-K_{g} A_{g}\left(\frac{T-T_{c}}{x}\right)
$$

Where; $\mathrm{Q}=$ heat

The following quantity of heat loss can be calculated using the expression below;

$\mathrm{PF}=$ Plywood front, $\mathrm{PS}=$ plywood side, $\mathrm{PB}=$ plywood back, $\mathrm{PT}=$ plywood top and bottom $\mathrm{gW}=$ glass window, $\mathrm{QL}=$ heat loss

Total heat that will be loss is given as

$$
Q_{L}=Q_{P T}+Q_{P S}+Q_{P B}+Q_{P F}+Q_{g W}
$$

DOI Number: https://doi.org/10.30780/IJTRS.V05.I02.002

Www.ijtrs.com

www.ijtrs.org 
This implies that, actual heat required for the system is given as;

$$
\mathrm{Q}=\mathrm{Q}_{\mathrm{L}}+\mathrm{Q}_{\mathrm{I}}
$$

\subsubsection{Design of Ventilation Holes}

Ventilation is basically the volume of mass flow in and out of the incubator, so the volume flow ratio is given as;

Volume flow rate $=$ Cross sectional area $\mathrm{x}$ velocity

Where

volume $=\frac{\pi \mathrm{d}^{2}}{4}$

$$
\text { Therefore the fan speed }=\frac{\pi \mathrm{d}^{2}}{4}
$$

Selection of DC Electric Motor

Torque generated by electric motor

Where $\mathrm{N}=$ speed in rpm

$$
\begin{array}{r}
\mathrm{T}_{\mathrm{m}}=\frac{\text { POWER }}{\text { ANGULAR VELOCITY }} \\
\text { i.e. } \mathrm{T}_{\mathrm{m}}=\frac{60 \times \text { POWER }}{2 \pi \mathrm{N}}
\end{array}
$$

\subsubsection{Design of Pulley}

The following designs were put into consideration before constructing the pulley;

$>$ Pulley diameters

$>$ The velocity ratio

$>$ Distance between driver and driven

$>$ Number of revolution of the drive

$>$ The power needed and tension of the tight and slack side

\subsubsection{Determination of Wood Strength to Support the Weight of Eggs}

The strength of the wood is been calculated using the normal formula; Taking into consideration of the loading due to the weight of the eggs;

Since they are uniformly distributed on the wood, the measurement carried out on the incubator is given as;

Length of plywood $=0.7 \mathrm{~m}$

Mass of plywood $\mathrm{mp}=2.40714 \mathrm{~kg}$

Mass of an egg $=0.0689 \mathrm{~kg}=$ weight of the egg

So the mass or weight of 50 eggs will be

Weight $=0.0689 \times 50=3.445 \mathrm{~kg}$

Weight $=3.445 \mathrm{~kg}$

Since the weight of the eggs is 3.445, then the UDL will be the weight of the egg divided by the total span of the wood which is $0.7 \mathrm{~m}$

$\mathrm{UDL}=\frac{\mathrm{We}}{\mathrm{L}}=\frac{3.445}{0.7} \times 9.81=0.04828 \mathrm{kN} / \mathrm{m}$

For a UDL: $\mathrm{R}_{\mathrm{A}}=\mathrm{R}_{\mathrm{B}}=\frac{\mathrm{W}}{2}$

$=\frac{0.04828 \times 0.7}{2}=0.016898 \mathrm{kN} / \mathrm{m}$

So the shear forces at point $\mathrm{A}$ and $\mathrm{B}$ will be

$$
\begin{aligned}
& \mathrm{S}_{\mathrm{A}}=\frac{\mathrm{Wl}}{2}=-0.016898 \mathrm{kN} \\
& \mathrm{S}_{\mathrm{B}}=\frac{\mathrm{wl}}{2}=0.016898 \mathrm{kN}
\end{aligned}
$$

So the bending moment at mid-point will be $\mathrm{M}_{\mathrm{c}}$

$$
\begin{aligned}
M_{c} & =\frac{W l}{8} \times l=\frac{0.04828 \times 0.7}{8} \times 0.7=2.95715 \times 10^{-3} \mathrm{kNm} \\
M_{c} & =2.95715 \mathrm{Nm}
\end{aligned}
$$

Then the heat loss in the incubator is derived through heat loss from the wooden walls, and the windows can be achieved using the conduction equation given as;

$$
\mathrm{Q}=-\mathrm{kA} \frac{\left(\mathrm{T}-\mathrm{T}_{\mathrm{s}}\right)}{\mathrm{X}}
$$

The heat loss through the top and bottom wall will be given as;

Area of $\mathrm{TB}=\mathrm{L} \times \mathrm{b}=60 \times 43=2580=0.258 \mathrm{~m} . \mathrm{sq}$

$\mathrm{A}=0.258 \mathrm{~m} . \mathrm{sq}$

$\mathrm{X}=0.015$

Therefore the heat loss through the top and bottom is;

$$
\mathrm{Q}_{\mathrm{TB}}=\left[-\frac{0.65 \times 0.258(12.8)}{0.015}\right] \times 2=-143.104 \times 2
$$

DOI Number: https://doi.org/10.30780/IJTRS.V05.I02.002

pg. 6

WWW.ijtrs.com

WWW.ijtrs.org 
$=-286.208$

$\mathrm{Q}_{\mathrm{TB}}=-0.286208 \mathrm{~W}$

The heat loss through side wooden wall is given by;

$\mathrm{A}=43 \mathrm{x} 43=0.1849 \mathrm{~m} . \mathrm{sq}$

$\mathrm{X}=0.015$

$Q_{s}=-0.205 \mathrm{w}$

$$
Q_{s}=\left[-\frac{0.65 \times 0.1849(12.8)}{0.015}\right]=-102.557867 \times 2=-205.115734
$$

The heat loss through the back wooden wall is given as;

Where; $A=60 \times 43=0.258 \mathrm{~m} . \mathrm{sq}$

$\mathrm{X}=0.015$

$\mathrm{Q}_{\mathrm{s}}=\frac{0.65 \times 0.258(12.8)}{0.015}=-143.104 \mathrm{~J}$

$Q=-0.143 \mathrm{~W}$

Heat loss through the glass window

Where; $\mathrm{A}=43 \times 22.5=0.09675 \mathrm{~m}$

$$
\begin{aligned}
& X=1 \\
& K=0.5
\end{aligned}
$$

Therefore; $Q_{g}=\frac{0.5 \times 0.09675(12.8)}{0.01}=-61.92 \mathrm{~J}$

$\mathrm{Q}=-0.06 \mathrm{~W}$

The heat loss through front wall is;

Where; $\mathrm{A}=2902.2=0.29025 \mathrm{~m} . \mathrm{sq}$

$\mathrm{X}=1.5=0.015 \mathrm{~m}$

$Q=-0.160992 W$

$$
Q_{F}=-\frac{0.65 \times 0.29025(12.8)}{0.015}=-160.992
$$

Then the total heat loss is given as;

$$
\begin{gathered}
Q_{L}=Q_{T B}+Q_{S}+Q_{B}+Q_{F}+Q_{G} \\
Q_{L}=(-0.286208-0.205-0.143-0.160992-0.06) W \\
Q_{L}=0.8552 W
\end{gathered}
$$

Having a total heat generated by the bulb to be $180 \mathrm{~W}$, therefore the remaining heat in the incubator will be $180-(0.8552+67.2296)=111.9152 \mathrm{~W}$

From the result and discussion so far, it was observed that the total heat generated inside the incubator is 180Watt; While the total heat used in raising the temperature of the incubator is (Qi $=67.2296 \mathrm{w}$ ) but the total heat losses through the plywood and glass window are $(\mathrm{QL}=0.8552 \mathrm{w})$.

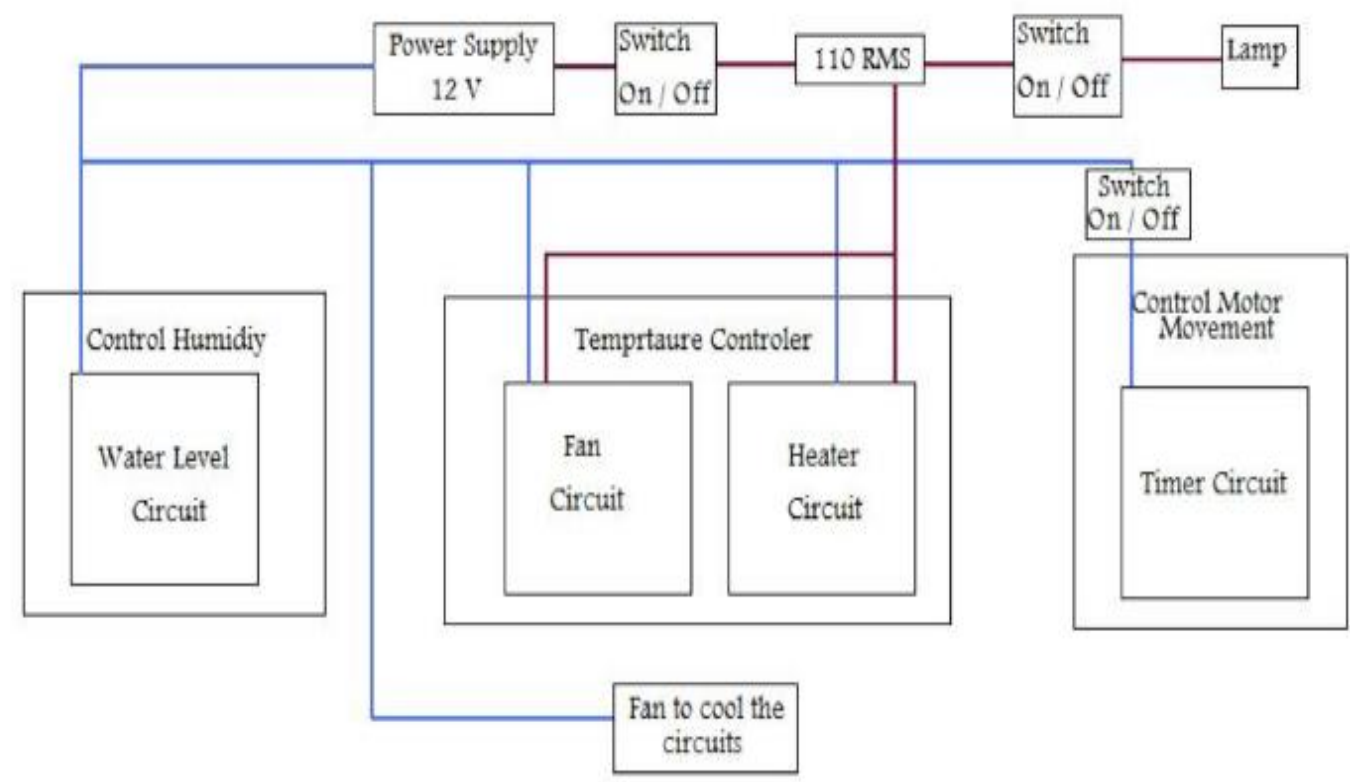

Fig. 2.4 Block Diagram Description

The connection of the three main block was represented by Figure 5; the egg incubator consists of three main blocks, which they are the temperature control block, humidity control block and motor control block. First off DOI Number: https://doi.org/10.30780/IJTRS.V05.I02.002

pg. 7

WWW.ijtrs.com

WWW.ijtrs.org 
F International Journal of Technical Research \& Science

all, the temperature control block contains fan circuit and heater circuit to supply temperature suitable for the eggs. The humidity control block consists of water level circuit to moisturize the eggs. Finally, motor movement control block consists of timer circuit that allows the motor to move from time to time. However, the motion is important for the egg to hatch, but not in all days. Therefore, this circuit has a switch connected to the power supply to open or close when necessary. All of them are supplied by 12 Volts power supply. That's why there is a switch connected to the power supply and the 110 RMS. It is the main switch that opens and closes the egg incubator, In addition, there was a small fan connected to the power supply so, it is on whenever the power supply is opened. This fan is to cool the circuits and increase the incubator's life. The incubator has a lamp to allow the user to see inner part of the device and also it can be used as addition heater if needed. The lamp has an external switch that connects it with 110 RMS to turn on/off depends on the user requirement (https://www.scribd.com/doc/46969946/Egg-Incubator-Project-Report, n.d.).

\section{RESULTS AND DISCUSSION}

\subsection{Result}

Table 3.1 shows the results of the Eggs incubation which revealed the following average result, 95 fertile Eggs, 85 hatched eggs and $89.47 \%$ hatchability.

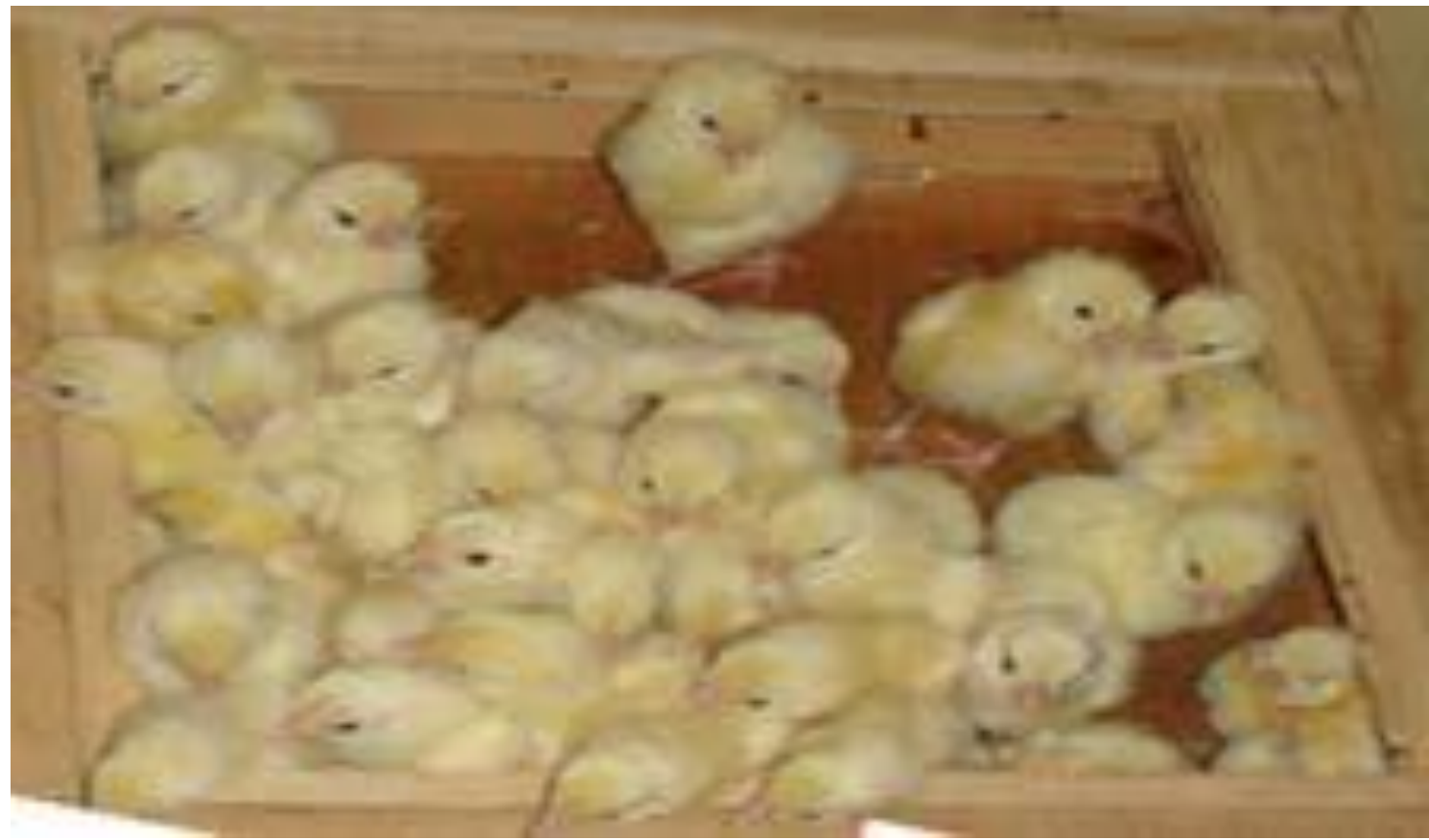

Fig. 3.1 Freshly Hatched Chicks

Another observation made over the same period was that the time response of the thermocouple was between 17-20 seconds. This implies that while the sensor maintained a constant incubating temperature of $39^{\circ} \mathrm{C}$, it takes sensor approximately 17 to 20 seconds to respond to a shift in temperature above or below $39^{\circ} \mathrm{C}$.

\subsection{Testing of the Incubator}

Before running the test, the incubator was protected from weather change by locating it indoor. The temperature and humidity were set and maintained uniformly between $37^{\circ}-39^{\circ} \mathrm{C}$ and $55 \%$ respectively. The ambient temperature and humidity were $33^{\circ} \mathrm{C}$ and $42 \%$. 100 fresh eggs were selected from breeders. The eggs were healthy, well developed and matured. The temperature and humidity were under control and monitored at every hour through the LCD. This process lasted for 21 days. The eggs were turned through an angle of $40^{\circ}$ either side of horizontal at every hour and this turning lasted for four minutes. The turning effect was (halted) on the 18th day. The eggs were candled alongside the incubation process as the experimentation continues. This was to determine the air space size in order to have a guide to the weight loss rate of the egg content. Also, to observe the development of the embryo so that infertile or dead embryo can be safely removed from the machine. Finally, on the 21 day hatching process took place. During this process close observation was made. Assistance was given to chicks during the hatch, for those chicks that failed to break the shell after 12 hours duration. The larger ends of eggs were broken, starting with the two holes slowly in line with literature (Raven, 1987). This procedure was repeated for the same number of eggs five (5) times in the first half of the year 2016, covering the month of January to June. This is described in Table 1. The incubation was powered by two standby generators during the process of evaluation to prevent the distortion that may tend to occur due to the inconsistent of the mains. The relationship in equation (21) was used to determine the hatchability of the machine.

DOI Number: https://doi.org/10.30780/IJTRS.V05.I02.002

pg. 8

wWw.ijtrs.com

WWW.ijtrs.org

Paper Id: IJTRS-V4-I12-010

Volume V Issue VII, August 2020 @ 2017, IJTRS All Right Reserved 


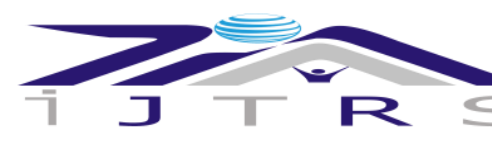

5 International Journal of Technical Research \& Science

Hatchability $=\frac{\text { Numbrer of hatched eggs }}{\text { number of fertile eggs }} \times 100$

Table-1.1 The Results of the Testing of Incubator

\begin{tabular}{|c|c|c|c|c|c|c|}
\hline Month & Trail & $\begin{array}{c}\text { Number of } \\
\text { Eggs set }\end{array}$ & Fertile Eggs & $\begin{array}{c}\text { Infertile } \\
\text { Eggs }\end{array}$ & $\begin{array}{c}\text { Hatched } \\
\text { Eggs }\end{array}$ & $\begin{array}{c}\text { Hatchability } \\
(\%)\end{array}$ \\
\hline January & 1 & 100 & 95 & 5 & 85 & 89.47 \\
\hline March & 2 & 100 & 92 & 8 & 88 & 95.57 \\
\hline April & 3 & 100 & 98 & 2 & 90 & 91.84 \\
\hline May & 4 & 100 & 96 & 4 & 85 & 88.54 \\
\hline June & 5 & 100 & 90 & 10 & 81 & 90.00 \\
\hline & Total & 500 & 471 & 39 & 429 & 455.42 \\
\hline & Average & 100 & 94.2 & 7.8 & 85.8 & 91.08 \\
\hline
\end{tabular}

\section{CONCLUSION}

The design of automatic incubator involved investigating heat transfer characteristics of Incubator cabinet. Mathematical model of cabinet was created and referred. After studying the reference factors for incubator, materials, size and other instrument were selected. The thermo-physical properties of selected materials were inserted to the equation of the incubator model to predict the possible of construction. From the calculation, the result showed that selected materials; such as zinc sheet, plywood and acrylic plastic sheet, were most suitable to construct the incubator cabinet.

The accuracy of measuring instruments was determined by using mercury thermometer and Testo 625 as standard. The error of temperature sensor was less than $1.1 \%$, whereas error of humidity sensor was under $5.3 \%$. This proofs the validity of sensors used as acceptable instruments and measurements approach adopted in the construction of the incubator was satisfactory. This work which focused on the design, construction and performance evaluation of an automatic turning mechanism egg incubator consumes less power and does not require continual presence of the operator. The machine will boost poultry farming in the country and beyond if it can be mass produced to assist farmers. The percentage hatchability of the incubator was $91 \%$ if operated within the operating range.

\section{RECOMMENDATION}

The authors would like to make the following recommendations which are worthy of note to add value to for further researches:

$>$ Performance evaluation of Incubators for other eggs such as turkey egg should be worked on so as to provide compressive information's for the design of incubators.

$>$ Motor with lower rating should be used to avoid high turning speed.

There's need for a constant supply of electricity to enable unobstructed operation of the incubator.

\section{REFERENCES}

[1] A.K., T. B. (2001). A test book of electrical technology.

[2] Adegbulugbe T. A., A. A. (2013). Development of an Automatic Electric Egg. International Journal of Scientific \& Engineering Research, 916.

[3] Anthony Obidiwe1, C. I. (n.d.). Design and Implementation of a Microcontroller Based.

[4] Anthony Obidiwe1, C. I. (n.d.). Design and Implementation of a Microcontroller Based. Abia State: University of Agriculture, Umudike,

[5] Benjamin and Oye, N. D. (2012). Modification of the Design of Poultry Incubator. International Journal of Application or Innovation in Engineering \& Management, 5-10.

[6] Benjamin N.and Oye, N. D. (2012). Modification of the Design of Poultry Incubator. International Journal of Application or Innovation in Engineering \& Management (IJAIEM), 2319 - 4847.

[7] C.E, A. W. (1986). poultry keeping. London: Oxford University press.

[8] D., C. (1990). The practical course of machine design. Minor publishermoscow.

[9] Ensminger, M. E. ((1974). Poultry Science,

[10] F.A, O. J. (1979). Poultry production in wet climate,. In Poultry production in wet climate (p. pg32.). London: Macmilla press.

[11] https://www.scribd.com/doc/46969946/Egg-Incubator-Project-Report. (n.d.).

[12] Kuphaldt, T. R. (2003). Retrieved from http-://www.allaboutcircuits.com/vol_3/chpt_4/2.html.

[13] LM35 Precision Centigrade Temperature Sensors, L. d. (2000, November). Retrieved from www.national.com/ds/LM/LM35.pdf.

[14] Lourens A.H, V. d. (2005.). Effect of eggshell temperature during incubation on embryo development.

[15] MohdAdid, A. M. (2008). Development of smart Egg Incubator System for Various types of Egg.

[16] Raven, H. (1987). Automatic Control Engineering. LONDON: Mc G Hill. 